\title{
Diagnosis and management of craniopharyngiomas in the era of genomics and targeted therapy
}

\author{
*Juan Carlos Martinez-Gutierrez, MD, ${ }^{1-3}$ Megan R. D’Andrea,, \\ Sandro Santagata, MD, PhD, ${ }^{5}$ Fred G. Barker II, MD, ${ }^{4}$ and Priscilla K. Brastianos, MD ${ }^{1,2}$ \\ 1Division of Hematology and Oncology, Department of Medicine, 'Division of Neuro-Oncology, Department of Neurology, \\ and ${ }^{4}$ Department of Neurological Surgery, Massachusetts General Hospital, Boston; ${ }^{5}$ Department of Pathology, Brigham and \\ Women's Hospital, Boston; and ${ }^{3}$ North Shore Medical Center, Salem, Massachusetts
}

\begin{abstract}
Craniopharyngiomas are rare intracranial neoplasms that pose clinical challenges due to their location adjacent to vital structures. The authors have previously shown high mutation rates of BRAF V600E in papillary craniopharyngioma and of CTNNB1 in adamantinomatous craniopharyngioma. These activating driver mutations are potential therapeutic targets, and the authors have recently reported a significant response to BRAF/MEK inhibition in a patient with multiply recurrent PCP. As these targetable mutations warrant prospective research, the authors will be conducting a national National Cancer Institute-sponsored multicenter clinical trial to investigate BRAF/MEK inhibition in the treatment of craniopharyngioma. In this new era of genomic discovery, the treatment paradigm of craniopharyngioma is likely to change. https://thejns.org/doi/abs/10.3171/2016.9.FOCUS16325
\end{abstract}

KEY WORDS craniopharyngioma; genomics; BRAF V600E; targeted therapy

$\mathrm{C}$ RANIOPHARYNGIOMAS are low-grade epithelial neoplasms that arise in the suprasellar region of the brain, adjacent to the optic nerves, brainstem, and pituitary gland. ${ }^{31}$ Patients with these tumors experience clinical deficits, including vision loss, headaches, pan-hypopituitarism, and hypothalamic dysfunction, due to damage to vital structures caused by aggressive tumor growth and therapeutic interventions. ${ }^{7,10,24}$ Surgery can be challenging in craniopharyngioma due to infiltration and compression of such structures as the hypothalamus, ventricular system, and cranial nerves. ${ }^{30}$ The incidence rate for craniopharyngioma is $0.18 / 100,000$, and craniopharyngiomas constitute $1 \%-3 \%$ of all brain tumors in the US. $7,14,24$

Craniopharyngiomas can be further classified into 2 histological subtypes, adamantinomatous and papillary. Adamantinomatous craniopharyngiomas (ACPs) occur in both children and adults, and have a histological appearance that is distinct from papillary craniopharyngiomas (PCPs), which mainly occur in adults (Table 1). Specifically, ACPs display whorls, cords, and lobules, with stellate reticulum, palisading peripheral columnar epithelium, and "wet" keratin. PCPs, on the other hand, have monomorphic squamous epithelium, fibrovascular cores, thin capillary blood vessels, and scattered immune cells. ${ }^{10,19}$ However, it is sometimes challenging to make a diagnosis based solely on histology, particularly for small biopsies that can be mistaken for other masses. ${ }^{43}$

In our recent study on craniopharyngiomas, we found notable mutations that can be used to distinguish between ACP and PCP. Specifically, we found that over $90 \%$ of PCPs have BRAF V600E mutations and that over $90 \%$ of ACPs have CTNNB1 mutations. ${ }^{6}$ These findings indicate the importance of genetics in both the diagnosis and clinical management of these tumors. While these 2 tumor types have traditionally been combatted with the same treatment options, genomic research has now revealed a potential for targeted therapies for craniopharyngiomas.

\section{Genetic Findings}

In line with its benign histological appearance, the genomic landscape of craniopharyngioma is relatively simple, with a nonsynonymous mutation rate of 0.9 per $\mathrm{Mb}$, which is comparable to that of other pediatric and lowgrade tumors (Fig. 1A). Moreover, mutations appear to arise from spontaneous deamination, with $58 \%$ of tumors

ABBREVIATIONS ACP = adamantinomatous craniopharyngioma; $P C P=$ papillary craniopharyngioma; $R C C=$ Rathke's cleft cyst.

SUBMITTED August 1, 2016. ACCEPTED September 22, 2016.

INCLUDE WHEN CITING DOI: 10.3171/2016.9.FOCUS16325.

* Drs. Santagata, Barker, and Brastianos contributed equally to this work. 
TABLE 1. Clinical and histological features of adamantinomatous and papillary craniopharyngiomas

\begin{tabular}{lll}
\hline \multicolumn{1}{c}{ Characteristic } & \multicolumn{1}{c}{ ACP } & PCP \\
\hline Patient population & Mostly children, some adults & Mostly adults \\
\hline Clinical presentation & Loss of vision, headaches, pituitary insufficiency & Loss of vision, headaches, pituitary insufficiency \\
\hline Histology & $\begin{array}{c}\text { Epithelium grows in whorls, cords, lobules; palisading periph- } \\
\text { eral columnar epithelium, stellate reticulum; "wet" keratin }\end{array}$ & $\begin{array}{c}\text { Well-differentiated monomorphic squamous epithelium; fibrovas- } \\
\text { cular cores, thin capillary blood vessels; scattered immune cells }\end{array}$ \\
\hline Genetics & CTNNB1 mutation (activation of Wnt pathway) & BRAF V600E mutation (activation of MAPK pathway) \\
\hline
\end{tabular}

having cytosine to thymidine changes at $\mathrm{CpG}$ dinucleotides (Fig. 1A). Interestingly, the vast majority of ACPs and PCPs harbor single exclusive clonal driver mutations in $C T N N B 1$ and $B R A F$, respectively. In our recent study, we found BRAF V600E in $94.4 \%$ of PCPs and none of the ACPs (Fig. 1B). CTNNB1 alterations in the exon 3 degradation-targeting motif were detected in $96 \%$ of the ACPs and none of the PCPs (Fig. 1B). Previous studies have reported CTNNB1 mutations, but only at $60 \%-75 \%$ frequency in ACPs. ${ }^{8,26,41}$ Interestingly, using immunohistochemistry we were able to detect the expression of these alterations with equal success (Fig. 2). Taken together, our findings, along with others, indicate an underlying genomic basis for histopathological classification and promising clinical detection tools for further study.

The BRAF V600E alteration has been well established as a driver mutation in other neoplasms. This alteration results in constitutive activation of the MAPK (or ERK) signaling pathway conferring growth advantage through modulation of cell proliferation, differentiation, and cell survival. Specifically, the RAS/RAF/MEK/ERK pathway is at the interface of extracellular and intracellular signaling as it translates hormone and growth factor cues into an oncogenic transcriptional program. In a normal state, RAS is GTP activated by these signals and it further activates RAF proteins including ARAF, BRAF, and CRAF. These RAS effectors activate MEKs and then downstream ERKs, master transcriptional regulators of c-Myc, c-Jun, and Ets-1, among others. BRAF V600E mutants are constitutively active, driving proliferation through constant activation of this MAPK network. ${ }^{36}$

Mutations in CTNNB1 have also been seen in other cancers. ${ }^{39}$ This driver mutation leads to accumulation of the protein $\beta$-catenin, which plays a role in cell signaling and cell adhesion. $\beta$-catenin is an important part of the Wnt signaling pathway, which promotes proliferation and differentiation of cells. When the Wnt pathway is inactive, $\beta$-catenin localizes to the cell membrane or the cytoplasm and is marked for degradation. Mutations in CTNNB1 activate the Wnt pathway, and $\beta$-catenin shifts into the cytoplasm and nucleus. ${ }^{35}$ Thus, $\beta$-catenin location can be used as an indicator of CTNNBI mutation status, which is readily assessed with standard immunohistochemical stains.

\section{Targeted Therapy in PCP}

Mutations in BRAF V600E have been observed and effectively targeted in other tumor types, including melanoma, ${ }^{15,16}$ ameloblastoma, ${ }^{20,27,42}$ hairy cell leukemia, ${ }^{12,13,17,23,}$ ${ }^{33,38}$ Erdheim-Chester disease, ${ }^{21,23}$ and pleomorphic xanthoastrocytoma. ${ }^{11,23,29,32}$ We recently achieved a clinically significant response in a patient with a recurrent BRAF V600E mutant PCP using targeted BRAF and MEK inhibitors $^{5}$ (Fig. 3). This patient had previously undergone multiple neurosurgical decompressions via craniotomy and suffered from bilateral optic neuropathy and panhypopituitarism due to the rapid growth of this large, cystic tumor. After 17 days of treatment with the BRAF inhibitor dabrafenib, the solid and cystic components of the tumor decreased by $50 \%$ and $70 \%$, respectively. For the next 14 days, the MEK inhibitor trametinib was added to the treatment regimen because of research indicating the potential for MEK inhibitors to prevent the development of resistance to BRAF inhibition in melanoma. ${ }^{15}$ This combined BRAF/MEK inhibition led to solid and cystic components of the tumor decreasing in total by $85 \%$ and $81 \%$, respectively. Following this targeted therapy, the patient underwent endoscopic transsphenoidal resection followed by radiotherapy. The patient is currently symptom free 18 months after radiation. Additionally, of note, we detected circulating BRAF V600E DNA in the patient's blood at multiple points during the treatment course. This finding indicates that a less-invasive "liquid biopsy" approach may someday be possible in the diagnosis of PCP.

While whole-exome sequencing data for our patient did not reveal any drivers of BRAF inhibitor resistance, possible resistance mechanisms must be kept in mind. A recent study reported an initial remarkable response of a PCP after treatment with the BRAF inhibitor vemurafenib. ${ }^{2}$ However, the patient in that case was not concurrently treated with a MEK inhibitor, and the tumor progressed after 6 weeks of treatment. Although this suggests the importance of MEK inhibition in the targeted treatment of BRAF mutated tumors, the role of BRAF monotherapy versus BRAF and MEK combination therapy needs to be prospectively studied.

Due to the genetic simplicity of craniopharyngiomas, there is great potential for targeted therapy as treatment for these neoplasms. While BRAF inhibitors such as vemurafenib and dabrafenib are currently available, agents that target the Wnt pathway are still in development. ${ }^{1,3}$ Thus, patients with PCP may immediately benefit from targeted therapy, whereas further studies must be done to develop targeted therapies for patients with ACP.

\section{Diagnostics}

The aforementioned genetic findings have crucial implications in the diagnosis of craniopharyngioma. Most notably, immunohistochemistry can now be used by pathologists to classify suprasellar tumors. One application of this is a recently developed mutation-specific antibody 

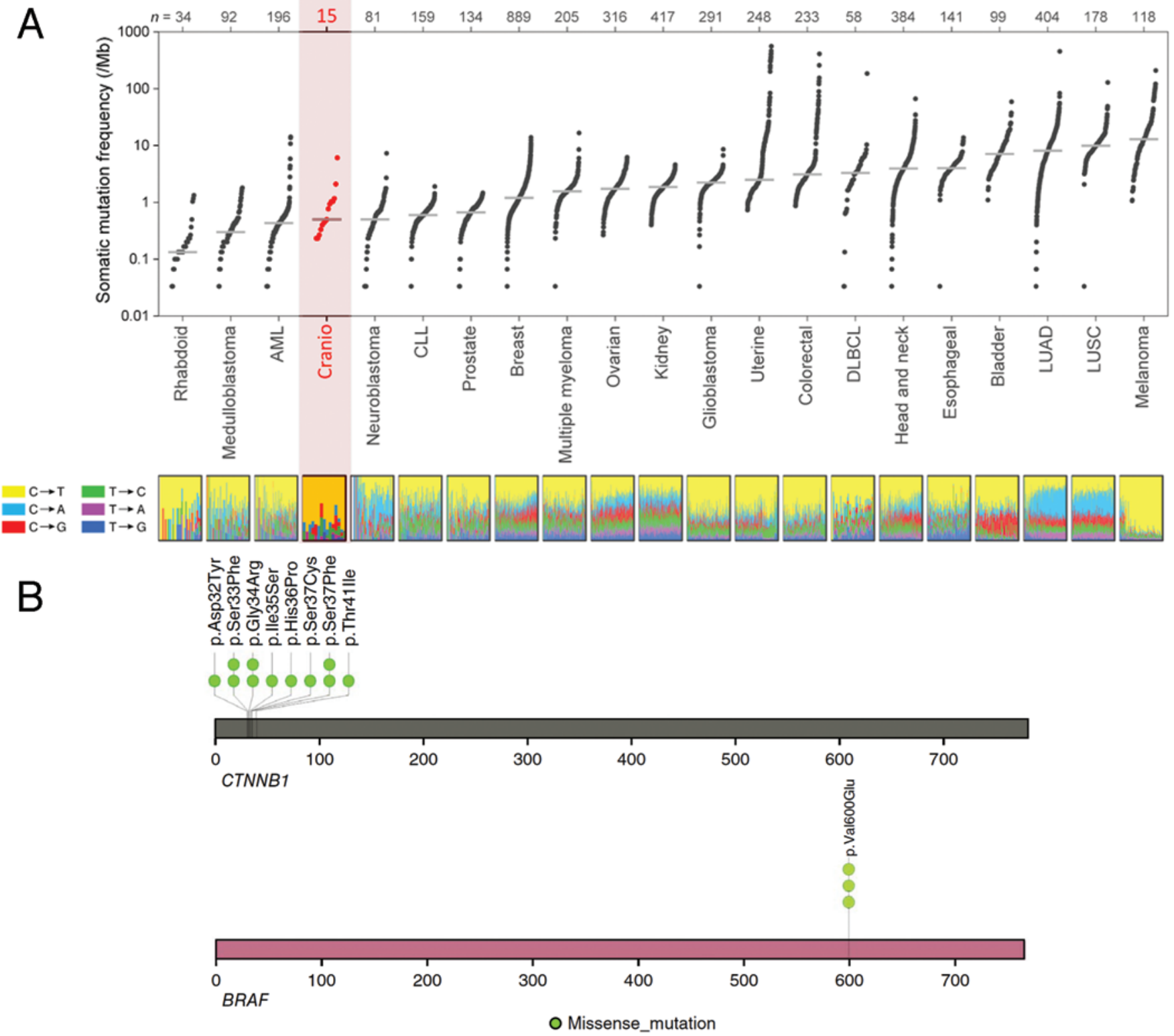

FIG. 1. A: Plot of mutation rate of craniopharyngiomas (red) compared with other tumors (black). Dots represent tumor-normal pairs. The $y$-axis is the mutation frequency, and the $x$-axis lists each tumor type, ordered from lowest mutation frequency to highest frequency. The mutational spectrum for each tumor is plotted on the bottom, with different colors representing different basepair substitutions. Craniopharyngiomas are low-mutation-rate tumors with a mutational spectrum consistent with spontaneous deamination, not consistent with a carcinogen-induced process. $A M L=$ acute myelogenous leukemia; $C L L=$ chronic lymphocytic leukemia; cranio = craniopharyngioma; $\mathrm{DLBCL}$ = diffuse large B-cell lymphoma; GBM = glioblastoma multiforme; $L U A D=$ lung adenocarcinoma; LUSC = lung squamous cell carcinoma. B: Location of CTNNB1 and BRAF mutations detected by whole-exome sequencing study of adamantinomatous and papillary craniopharyngiomas in their corresponding protein sequences. All CTNNB1 mutations were located in exon 3 exclusively. All BRAF mutations were activating V600E mutations. Both images reproduced with permission from Brastianos PK, Taylor-Weiner A, Manley PE, Jones RT, Dias-Santagata D, Thorner AR, et al: Exome sequencing identifies BRAF mutations in papillary craniopharyngiomas. Nat Genet 46:161-165, 2014.

(VE1) that recognizes BRAF V600E mutant protein, which can be used to differentiate between ACP and PCP. ${ }^{9}$ Staining for BRAF V600E can also help to assess lesions such as Rathke's cleft cysts (RCCs), which can be confused with craniopharyngiomas, particularly when the cyst lining has undergone extensive squamous metaplasia. A recent study examined 33 lesions that were originally diagnosed as RCCs and reclassified 3 of them as PCP based on $B R A F$ status..$^{40}$ A caveat to this is that one must take care in examining immunohistochemical specimens for $B R A F$ status, as the VE1 antibody has been shown to react with certain BRAF WT tissues, such as normal cells in the anterior pituitary as well as ciliated epithelial cells. ${ }^{4,25,28,37}$ Immunohistochemistry can also be used to diagnose craniopharyngioma based on CTNNB1 status. In $\mathrm{PCP}, \beta$-catenin is localized to the cell membrane, whereas 


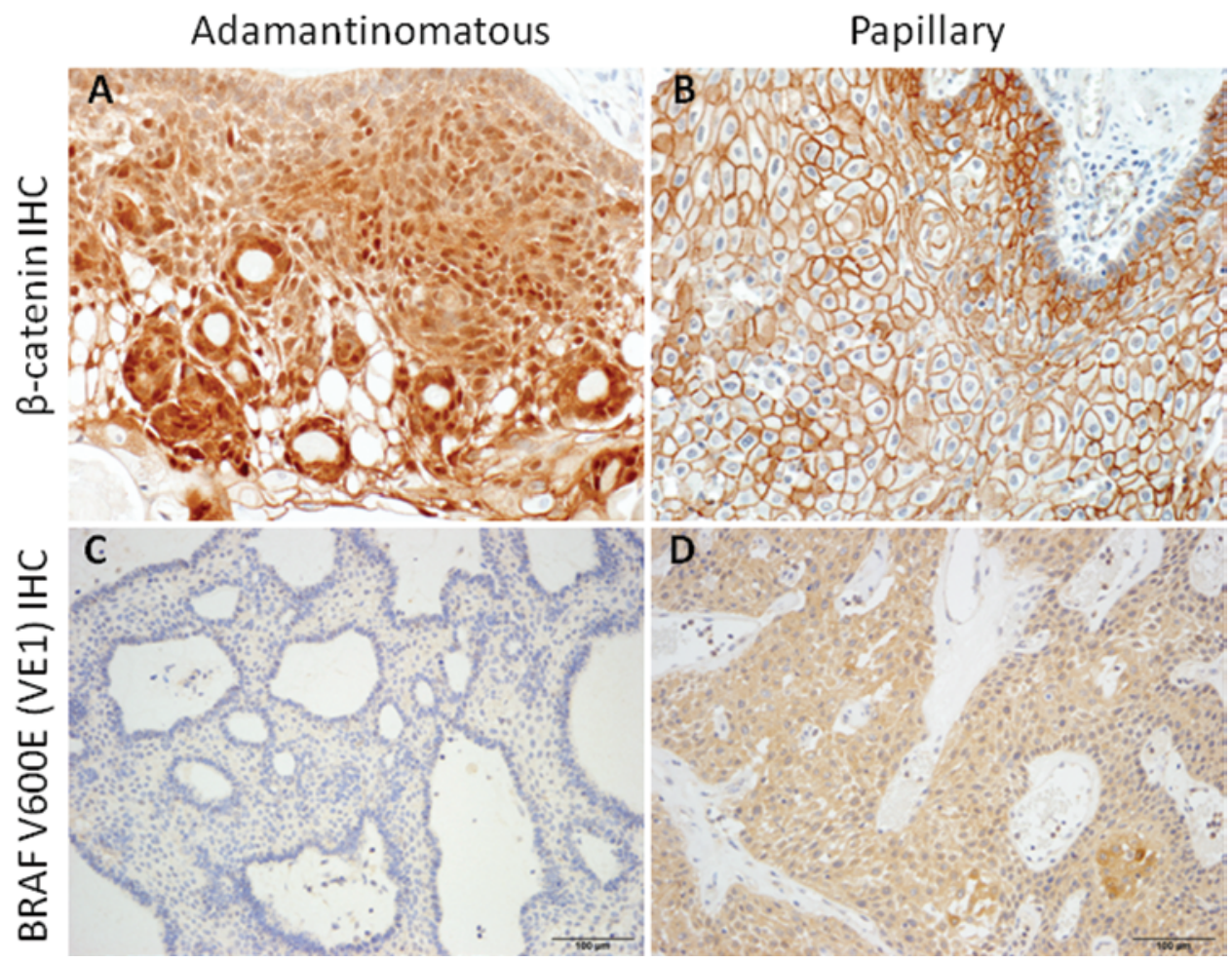

FIG. 2. Immunohistochemical staining for $\beta$-catenin (A and B) and BRAF V600E (C and D) in craniopharyngiomas. ACPs show localization of $\beta$-catenin to the cytoplasm and nucleus $(A)$, which is a marker of activated $\beta$-catenin. PCPs show localization of $\beta$-catenin to the cell membrane (B). In contrast, ACPs were negative for $\mathrm{V} 600 \mathrm{E}(\mathrm{C})$ and PCPs were positive for $\mathrm{V} 600 \mathrm{E}(\mathrm{D})$. IHC = immunohistochemistry. Bar $=100 \mu \mathrm{m}$. Figure reproduced with permission from Brastianos PK, Taylor-Weiner A, Manley PE, Jones RT, Dias-Santagata D, Thorner AR, et al: Exome sequencing identifies BRAF mutations in papillary craniopharyngiomas. Nat Genet 46:161-165, 2014.

in ACP $\beta$-catenin is seen in the cytoplasm and nucleus, which is a marker of activated $\beta$-catenin. ${ }^{18,22,34,35}$ Notably, nuclear localization of $\beta$-catenin is not uniform through the neoplastic epithelium of ACPs, and is found rather in both scattered individual cells as well as clusters of cells. Thus, staining for $\beta$-catenin could highlight the specific classification of a craniopharyngioma. Although immunohistochemistry is a powerful tool for the diagnosis of these suprasellar tumors, genetic testing alone may be sufficient in making craniopharyngioma diagnoses.

\section{Clinical Trial}

We will be conducting a Phase II, National Cancer Institute-sponsored multicenter national clinical trial investigating BRAF/MEK inhibitors in patients with PCP,
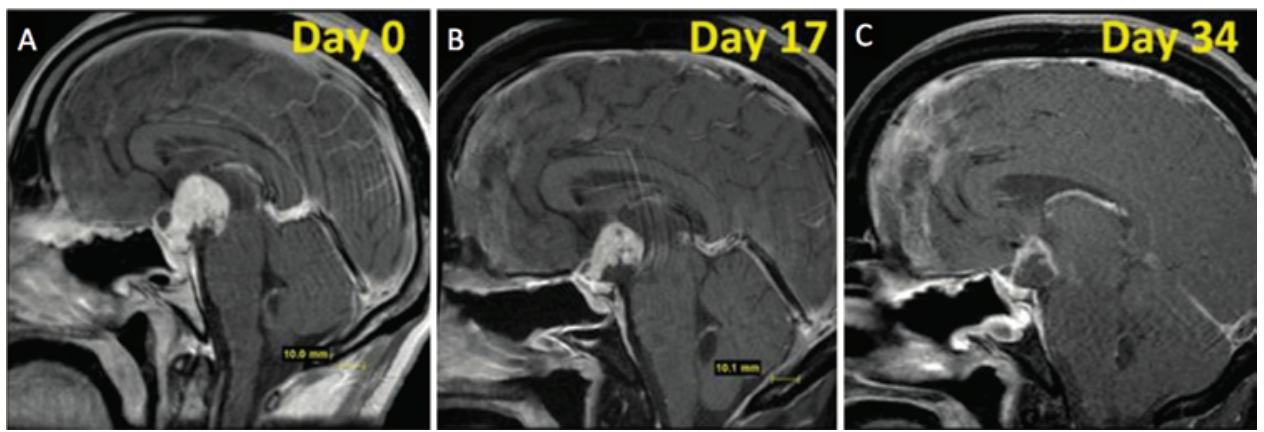

FIG. 3. Sagittal T1-weighted contrast-enhanced MR images showing the response of a patient with a multiply recurrent craniopharyngioma to targeted therapy. A: Image obtained prior to initiation of therapy showing recurrent craniopharyngioma. B: Image obtained 17 days after initiation of treatment with the BRAF inhibitor dabrafenib showing a 52\% decrease in the enhancing tumor volume. C: Image obtained after 14 additional days of treatment with dabrafenib and the MEK inhibitor trametinib showing an $85 \%$ volumetric reduction in the enhancing tumor volume. Figure reproduced from Brastianos PK, Shankar GM, Gill CM, Taylor-Weiner A, Nayyar N, Panka DJ, et al: Dramatic response of BRAF V600E mutant papillary craniopharyngioma to targeted therapy. J Natl Cancer Inst 108:djv310, 2016. Published with permission from Oxford University Press. 
likely to begin accrual in early 2017. In addition to slowing the development of resistance to BRAF inhibitors, MEK inhibitors have been shown to prevent the formation of squamous-cell carcinoma, which is a complication of BRAF-inhibitor treatment. Thus, we will be exploring the combination of BRAF and MEK inhibitors as a systemic treatment plan. Through this study, pre- and posttreatment tissue will be obtained for whole exome sequencing as well as RNA sequencing to study the genetic drivers of these tumors. Additionally, based on the discovery of circulating BRAF V600E in our patient, we will be testing blood for cell-free DNA throughout the clinical trial.

\section{Conclusions}

The research outlined in this review highlights the potential for neoadjuvant approaches in the treatment of craniopharyngioma in patients with specific mutations. It is clear that clonal mutations in the evolution of these genetically simple tumors are crucial for tumor growth and can be targeted by drug therapies. While craniopharyngiomas are traditionally treated with surgery and radiation, it is possible that targeted therapy could reduce the morbidities associated with traditional treatments and lead to better outcomes for patients with these tumors.

\section{References}

1. Anastas JN, Moon RT: WNT signalling pathways as therapeutic targets in cancer. Nat Rev Cancer 13:11-26, 2013

2. Aylwin SJ, Bodi I, Beaney R: Pronounced response of papillary craniopharyngioma to treatment with vemurafenib, a BRAF inhibitor. Pituitary 19:544-546, 2016

3. Basu A, Bodycombe NE, Cheah JH, Price EV, Liu K, Schaefer GI, et al: An interactive resource to identify cancer genetic and lineage dependencies targeted by small molecules. Cell 154:1151-1161, 2013

4. Bösmüller H, Fischer A, Pham DL, Fehm T, Capper D, von Deimling A, et al: Detection of the BRAF V600E mutation in serous ovarian tumors: a comparative analysis of immunohistochemistry with a mutation-specific monoclonal antibody and allele-specific PCR. Hum Pathol 44:329-335, 2013

5. Brastianos PK, Shankar GM, Gill CM, Taylor-Weiner A, Nayyar N, Panka DJ, et al: Dramatic response of BRAF V600E mutant papillary craniopharyngioma to targeted therapy. J Natl Cancer Inst 108:djv310, 2016

6. Brastianos PK, Taylor-Weiner A, Manley PE, Jones RT, DiasSantagata D, Thorner AR, et al: Exome sequencing identifies BRAF mutations in papillary craniopharyngiomas. Nat Genet 46:161-165, 2014

7. Bunin GR, Surawicz TS, Witman PA, Preston-Martin S, Davis F, Bruner JM: The descriptive epidemiology of craniopharyngioma. Neurosurg Focus 3(6):e1, 1997

8. Buslei R, Nolde M, Hofmann B, Meissner S, Eyupoglu IY, Siebzehnrübl F, et al: Common mutations of $\beta$-catenin in adamantinomatous craniopharyngiomas but not in other tumours originating from the sellar region. Acta Neuropathol 109:589-597, 2005

9. Capper D, Preusser M, Habel A, Sahm F, Ackermann U, Schindler G, et al: Assessment of BRAF V600E mutation status by immunohistochemistry with a mutation-specific monoclonal antibody. Acta Neuropathol 122:11-19, 2011

10. Crotty TB, Scheithauer BW, Young WF Jr, Davis DH, Shaw EG, Miller GM, et al: Papillary craniopharyngioma: a clinicopathological study of 48 cases. J Neurosurg 83:206-214, 1995
11. Dias-Santagata D, Lam Q, Vernovsky K, Vena N, Lennerz JK, Borger DR, et al: BRAF V600E mutations are common in pleomorphic xanthoastrocytoma: diagnostic and therapeutic implications. PLoS One 6:e17948, 2011

12. Dietrich S, Glimm H, Andrulis M, von Kalle C, Ho AD, Zenz T: BRAF inhibition in refractory hairy-cell leukemia. N Engl J Med 366:2038-2040, 2012

13. Dietrich S, Hüllein J, Hundemer M, Lehners N, Jethwa A, Capper D, et al: Continued response off treatment after BRAF inhibition in refractory hairy cell leukemia. J Clin Oncol 31:e300-e303, 2013

14. Dolecek TA, Propp JM, Stroup NE, Kruchko C: CBTRUS statistical report: primary brain and central nervous system tumors diagnosed in the United States in 2005-2009. Neuro Oncol 14 (Suppl 5):v1-v49, 2012

15. Flaherty KT, Infante JR, Daud A, Gonzalez R, Kefford RF, Sosman J, et al: Combined BRAF and MEK inhibition in melanoma with BRAF V600 mutations. N Engl J Med 367:1694-1703, 2012

16. Flaherty KT, Puzanov I, Kim KB, Ribas A, McArthur GA, Sosman JA, et al: Inhibition of mutated, activated BRAF in metastatic melanoma. N Engl J Med 363:809-819, 2010

17. Follows GA, Sims H, Bloxham DM, Zenz T, Hopper MA, Liu H, et al: Rapid response of biallelic BRAF V600E mutated hairy cell leukaemia to low dose vemurafenib. Br J Haematol 161:150-153, 2013

18. Gaston-Massuet C, Andoniadou CL, Signore M, Jayakody SA, Charolidi N, Kyeyune R, et al: Increased Wingless (Wnt) signaling in pituitary progenitor/stem cells gives rise to pituitary tumors in mice and humans. Proc Natl Acad Sci U S A 108:11482-11487, 2011

19. Giangaspero F, Burger PC, Osborne DR, Stein RB: Suprasellar papillary squamous epithelioma ("papillary craniopharyngioma"). Am J Surg Pathol 8:57-64, 1984

20. Gomes CC, Diniz MG, Gomez RS: Progress towards personalized medicine for ameloblastoma. J Pathol 232:488-491, 2014

21. Haroche J, Cohen-Aubart F, Emile JF, Maksud P, Drier A, Tolédano D, et al: Reproducible and sustained efficacy of targeted therapy with vemurafenib in patients with $\mathrm{BRAF}^{\mathrm{V} 600 \mathrm{E}_{-}}$ mutated Erdheim-Chester disease. J Clin Oncol 33:411-418, 2015

22. Hofmann BM, Kreutzer J, Saeger W, Buchfelder M, Blümcke I, Fahlbusch R, et al: Nuclear $\beta$-catenin accumulation as reliable marker for the differentiation between cystic craniopharyngiomas and Rathke cleft cysts: a clinico-pathologic approach. Am J Surg Pathol 30:1595-1603, 2006

23. Hyman DM, Puzanov I, Subbiah V, Faris JE, Chau I, Blay JY, et al: Vemurafenib in multiple nonmelanoma cancers with BRAF V600 mutations. N Engl J Med 373:726-736, 2015

24. Jane JA Jr, Laws ER: Craniopharyngioma. Pituitary 9:323326,2006

25. Jones RT, Abedalthagafi MS, Brahmandam M, Greenfield EA, Hoang MP, Louis DN, et al: Cross-reactivity of the BRAF VE1 antibody with epitopes in axonemal dyneins leads to staining of cilia. Mod Pathol 28:596-606, 2015

26. Kato K, Nakatani Y, Kanno H, Inayama Y, Ijiri R, Nagahara $\mathrm{N}$, et al: Possible linkage between specific histological structures and aberrant reactivation of the Wnt pathway in adamantinomatous craniopharyngioma. J Pathol 203:814-821, 2004

27. Kaye FJ, Ivey AM, Drane WE, Mendenhall WM, Allan RW: Clinical and radiographic response with combined BRAFtargeted therapy in stage 4 ameloblastoma. J Natl Cancer Inst 107:378, 2014

28. Kim JH, Paulus W, Heim S: BRAF V600E mutation is a useful marker for differentiating Rathke's cleft cyst with squamous metaplasia from papillary craniopharyngioma. J Neurooncol 123:189-191, 2015 
29. Lee EQ, Ruland S, LeBoeuf NR, Wen PY, Santagata S: Successful treatment of a progressive BRAF V600E-mutated anaplastic pleomorphic xanthoastrocy toma with vemurafenib monotherapy. J Clin Oncol 34:e87-e89, 2016

30. Liubinas SV, Munshey AS, Kaye AH: Management of recurrent craniopharyngioma. J Clin Neurosci 18:451-457, 2011

31. Louis DN, Ohgaki H, Wiestler OD, Cavenee WK: WHO Classification of Tumours of the Central Nervous System, ed 4. Lyon, France: International Agency for Research on Cancer, 2007, pp 238-240

32. MacConaill LE, Campbell CD, Kehoe SM, Bass AJ, Hatton $\mathrm{C}$, Niu L, et al: Profiling critical cancer gene mutations in clinical tumor samples. PLoS One 4:e7887, 2009

33. Maevis V, Mey U, Schmidt-Wolf G, Schmidt-Wolf IGH: Hairy cell leukemia: short review, today's recommendations and outlook. Blood Cancer J 4:e184, 2014

34. Martinez-Barbera JP: Molecular and cellular pathogenesis of adamantinomatous craniopharyngioma. Neuropathol Appl Neurobiol 41:721-732, 2015

35. Martinez-Barbera JP, Buslei R: Adamantinomatous craniopharyngioma: pathology, molecular genetics and mouse models. J Pediatr Endocrinol Metab 28:7-17, 2015

36. Michaloglou C, Vredeveld LC, Mooi WJ, Peeper DS: $\mathrm{BRAF}^{\mathrm{E} 600}$ in benign and malignant human tumours. Oncogene 27:877-895, 2008

37. Mordes DA, Lynch K, Campbell S, Dias-Santagata D, Nose V, Louis DN, et al: VE1 antibody immunoreactivity in normal anterior pituitary and adrenal cortex without detectable BRAF V600E mutations. Am J Clin Pathol 141:811-815, 2014

38. Munoz J, Schlette E, Kurzrock R: Rapid response to vemurafenib in a heavily pretreated patient with hairy cell leukemia and a BRAF mutation. J Clin Oncol 31:e351-e352, 2013

39. Polakis P: The many ways of Wnt in cancer. Curr Opin Genet Dev 17:45-51, 2007

40. Schweizer L, Capper D, Hölsken A, Fahlbusch R, Flitsch J,
Buchfelder M, et al: BRAF V600E analysis for the differentiation of papillary craniopharyngiomas and Rathke's cleft cysts. Neuropathol Appl Neurobiol 41:733-742, 2015

41. Sekine S, Shibata T, Kokubu A, Morishita Y, Noguchi M, Nakanishi Y, et al: Craniopharyngiomas of adamantinomatous type harbor $\beta$-catenin gene mutations. Am J Pathol 161:1997-2001, 2002

42. Sweeney RT, McClary AC, Myers BR, Biscocho J, Neahring L, Kwei KA, et al: Identification of recurrent SMO and BRAF mutations in ameloblastomas. Nat Genet 46:722-725, 2014

43. Zada G, Lin N, Ojerholm E, Ramkissoon S, Laws ER: Craniopharyngioma and other cystic epithelial lesions of the sellar region: a review of clinical, imaging, and histopathological relationships. Neurosurg Focus 28(4):E4, 2010

\section{Disclosures}

Dr. Brastianos reports being a consultant for Angiochem and Genentech and has received honoraria from Merck. Dr. Cahill has received honoraria from Merck.

\section{Author Contributions}

Conception and design: all authors. Acquisition of data: all authors. Analysis and interpretation of data: all authors. Drafting the article: all authors. Critically revising the article: all authors. Reviewed submitted version of manuscript: all authors. Approved the final version of the manuscript on behalf of all authors: Brastianos. Study supervision: Brastianos, Cahill, Santagata, Barker.

\section{Correspondence}

Priscilla K. Brastianos, Department of Medicine, Massachusetts General Hospital and Harvard Medical School, 55 Fruit St., YAW 9E, Boston, MA 02114. email: pbrastianos@partners.org. 